\section{Questión}

Periodismo / Comunicación ISSN 1669-6581
- Av. $44 \mathrm{~N}^{\circ} 676,1^{\circ}$ piso

CP 1900 - La Plata - Argentina

www.perio.unlp.edu.ar/question

La pandemia, la vida cotidiana y la Universidad

María Sofía Bernat

DOI: https://doi.org/10.24215/16696581e308

\title{
La pandemia, la vida cotidiana y la Universidad
}

\section{The pandemic, everyday life and the University}

María Sofía Bernat / sofiabernat@gmail.com Integrante de la Dirección de Redes Intersectoriales en Salud de la Universidad Nacional de La Plata. Doctora en Comunicación y Licenciada en Comunicación Social con Orientación en Periodismo (FPyCS-UNLP). Ex becaria interna doctoral y posdoctoral del CONICET (2013-2020). Becaria Presidente Néstor Kirchner en el período 2017-2018

(The New School y UNSAM).

Otra vez habitamos un incidente que nos toca de cerca y modifica nuestra vida cotidiana. Pero a diferencia del anterior, la inundación de 2013, éste nos descoloca de nuestro lugar ameno de respuesta: los encuentros. La emergencia sanitaria y el aislamiento social preventivo obligatorio dispuesto a partir de la pandemia de COVID-19 nos impiden encontrarnos offline para reflexionar e imaginar qué hacer, es decir, evitan que nos veamos, juntemos, expresemos, pensemos cara a cara. Sin embargo, ello no imposibilita actuar y analizar de forma colectiva. $Y$ mucho menos cuando lo hacemos desde la Universidad.

Algunos/as autores/as señalan que el biopoder y el neoliberalismo históricamente han buscado descolectivizar, es decir, construir políticas para que cada individuo se quede en su lugar, anulando cualquier sentido de pertenencia. En la actualidad, el aislamiento puede ser leído en esa línea, pero aún en aquellos casos en los que se lo transita en soledad, entendemos que se vuelve una forma de pertenecer a un colectivo. Sin caer en heroísmos o en castigos demoledores y acusaciones hacia cada enfermo/a, cumplir el aislamiento parece convertirse en una tarea cuasi patriótica, que se aleja del "sálvese quien pueda" para subrayar: nos tenemos 
que salvar entre todos/as y sin violencias. Esa es quizás hoy la forma de producir encuentros, puntos compartidos.

Decíamos que la pandemia incide en nuestra cotidianidad y eso es fundamental porque sabemos que allí se condensan los sentidos que le damos al mundo y una serie de certezas que hemos naturalizado sin discusión. Para la investigadora mexicana Rossana Reguillo (2005), la vida cotidiana es una perspectiva poseedora de una dimensión productiva y constitutiva. Afirma que "resulta urgente hacerla salir de la clandestinidad, desplegar su potencia a través del análisis, como condición necesaria para comprender lo social" (Reguillo, 2005, p. 315) y agrega que implica reproducción sociocultural, pero que también permite una reapropiación de nuestra existencia. $Y$ es esa existencia la que se ha visto disputada ante la emergencia sanitaria y el aislamiento social.

Si la sucesión de certezas se pone en cuestión, ¿qué ocurre, entonces, con la Universidad? Las prácticas que llevamos a cabo día a día se ven interrumpidas y parece que, en lo inmediato, todo cambia. Pero ¿en qué medida es así? Las instituciones tienen que necesariamente repensarse, redefinirse, o quizás, reacomodarse al contexto con sus prioridades históricas: la ampliación del acceso a derechos; la conquista del derecho a la salud, enfatizamos desde la Dirección de Redes Intersectoriales en Salud de la Universidad Nacional de La Plata (UNLP).

\section{El rol de la Universidad}

Desde su inicio, esta Dirección se propone construir un espacio de conocimiento e iniciativas académicas y pedagógicas integrales para la formación de profesionales de la salud con vocación sanitaria, perspectiva de derechos, de género e interdisciplinaria y con responsabilidad social. A su vez, pretende generar propuestas propias de gestión en temas competentes a la salud que refuercen la articulación de la UNLP con el sistema de salud regional, fortaleciendo el primer nivel de atención y las redes territoriales, para garantizar el acceso a una atención y a una formación de calidad.

En este contexto y como parte de dicha casa de altos estudios, la Dirección acompaña el trabajo de la UNLP, entendiendo que se trata de un actor clave en la región que, desde el comienzo, lleva a cabo diferentes acciones: el albergue universitario ha sido acondicionado como hospital de campaña, hay facultades que realizan testeos de COVID-19, se producen 
iniciativas solidarias en barrios populares para intentar garantizar que no falten alimentos y artículos de limpieza, se investiga durante el aislamiento, entre otras.

Una propuesta que queremos destacar es que la Universidad articula con organismos provinciales y municipales la puesta en marcha de una convocatoria a voluntarios/as para efectuar tareas de prevención y acompañamiento en diferentes instituciones. Específicamente, esta convocatoria es organizada por la Secretaría de Salud, la Secretaría de Extensión, el Consejo Social, la Asociación de Trabajadores de la UNLP, la Asociación de Docentes de la UNLP, la Federación Universitaria de La Plata y la mencionada Dirección de Redes Intersectoriales en Salud.

Hay inscriptos 1600 estudiantes y graduados/as de las carreras de Ciencias Médicas, Trabajo Social, Ciencias Económicas, Comunicación e Informática. El objetivo no es sólo realizar un aporte concreto al sistema de salud durante la pandemia, sino también construir conocimientos sobre las prácticas emprendidas desde los distintos campos de saberes. Así, desde la Dirección nos comprometemos a indagar y relevar información en la emergencia sanitaria en vistas a producir algún tipo de dato que incida sobre nuestras prácticas para mejorarlas. Porque sabemos que son perfectibles y en una pandemia eso queda claro: todo tiene que ser revisado porque todo es puesto en cuestión. La vida cotidiana para esta institución es ahora más que nunca estar -de diversas y nuevas formas- en el campo, sistematizar, pensar, comunicar e incidir para transformar. Y, siguiendo a Jorge González Sánchez, partimos de una pregunta, que más que pregunta es la retórica de una certeza: "Si la Universidad no está donde duele, ¿dónde va a estar?".

Sin hacer apología del saber experto -en especial, del médico hegemónico-, luego de años en los que se vapuleó y desacreditó a la ciencia, observamos el espesor político y práctico que asume la Universidad. El desprestigio no sólo ha sido económico, sino también fuertemente simbólico: se puso en cuestión el papel y la utilidad de las instituciones que producen conocimientos. Pero hoy, ante una crisis sociosanitaria, dichas instituciones salen a relucir y a poner en práctica el valor -que debe ser reconocimiento- de aprender y de construir saberes que amplíen derechos por y para el pueblo. Ese es el camino que hemos de caminar.

En el futuro, esperamos que la Universidad también desempeñe un rol clave: el de formular y asumir los dolorosos interrogantes que nacen (o persisten) luego de una pandemia: la pregunta por los modos de producción, los vínculos sociedad-naturaleza, la economía de mercado, la 
comunicación mercantilista, sojuzgadora y amarillista, los sujetos, los estigmas, los lazos sociales, las desigualdades, la violencia de género en todas sus modalidades, las injusticias territoriales...

Repensar y construir de nuevo. No desde los escombros. No desde las cenizas. Desde el lugar de los acontecimientos, como lo han venido haciendo algunos/as comunicadores/as, médicos/as, etnográfos/as y todas las personas que se inquietan ante las injusticias. Pues los tercos hechos evidencian una vez más que, mientras tambalean algunas certezas, otras ideas persisten, como diría Galeano, porfiadamente vivas: la salud es un derecho y el Estado debe garantizarlo.

Bibliografía

- Galeano, Eduardo. (2007). El libro de los abrazos. Buenos Aires. Catálogos.

- Reguillo, Rossana. (2005). La construcción simbólica de la ciudad. Sociedad, desastre y comunicación. Guadalajara. Universidad Iberoamericana/ITESO.

Otras

- Seminario "Cultura, producción de sentido y formación de subjetividad" dictado por Jorge González Sánchez en la Facultad de Periodismo y Comunicación Social de la Universidad Nacional de La Plata del 1 al 5 de julio de 2013. 